\title{
LA EVOLUCIÓN DE LA TEORfA DE LA HISTORIA DEL ARTE POR ESCRITORES DEL SIGLO XX SOBRE EL ARTE MEXICANO DEL SIGLO XIX *
}

Por John F. Scott

Con excepción de algunos escritores de principios del siglo $\mathrm{xx}$ que tenían gusto e interés por el arte del siglo $\mathrm{xIX}$, como antecedente inmediato de su actualidad, los mexicanos de nuestra centuria en su mayoría se han interesado en el arte del XIX como origen de algunos rasgos del renacimiento artístico de los años veintes. Haciendo esfuerzos por seguir el espíritu nacional en las expresiones de Rivera y Orozco yéndose hacia atrás hasta las culturas precortesianas, los escritores como Charlot han tratado de recrear los antecedentes en que surgió el desarrollo moderno. Hace poco tiempo que empezó el interés por tratar de entender el siglo anterior en sus propios términos, no solamente como sobrevivencia del esplendor virreinal ni como prólogo a las creaciones modernas. Este esfuerzo ha creado la necesidad de investigaciones nuevas para determinar y evaluar los hechos de ese periodo, anteriormente rechazado, sobre todo los que se refieren a la Academia de San Carlos. De esta nueva búsqueda de hechos ha resultado una mejor consideración, menos polémica, del valor y las limitaciones de cada artista del periodo y de sus obras particulares.

La historiografía siguiente de escritos del siglo $\mathrm{xx}$ sobre el arte mexicano del siglo XIX, ha sido originada considerando en su orden cronológico los del primer rango, que han cambiado la dirección de estudios posteriores. Los del segundo rango, o sea derivativos, no caben siempre en ese orden cronológico, pero se relacionan con las obras escritas que los inspiraron.

Puesto que la primera década del siglo $\mathrm{xx}$ continúa políticamente el Porfiriato del último cuarto del siglo xix, Manuel G. Revilla, el primer escritor del siglo $\mathrm{xx}$, debe ser considerado como una extensión de la crítica académica del siglo xix. Su libro El arte en México, de 1893, es el primer ensayo que sintetizó el proceso entero del arte mexicano desde la Conquista. Extrañamente, no considera entre los artistas del siglo xIX sino a los escultores, y de ellos no más a los continuadores de los temas religiosos de la Nueva España. Presta mucha atención a la

- Trabajo realizado en el Seminario de Tesis de Historia del Arte, del Dr. Jus. tino Fernández. 
familia poblana Cora, que continuaba el arte religioso de estilo colonial hasta los años de 1890 . Revilla considera que la "verdadera" escultura (la académica) fue introducida por Manuel Tolsá, y menciona sólo a aquellos escultores que continuaron ese estilo, como Mariano Perusquía y Mariano Arce, en los temas religiosos de sus obras queretanas. Dedica atención a Pedro Patiño Ixtolinque por ser indio, dato que trata como curiosidad y no como prueba moral, y por su "saber, empeño y finura de ejecución, pero no gran originalidad". Pero con la extinción del estilo colonial, Revilla deja el tema de la escultura y no examina su renacimiento en la Academia del siglo xix bajo la dirección de Vilar.

En sus escritos siguientes, recopilados en 1908 intitulados Obras; bio grafias (artistas), Revilla si empezó a interesarse en las biografías de las mayores personalidades en la Academia del siglo xix, incluyendo pintores, arquitectos, escultores y compositores. Las informaciones históricas all presentadas fueron utilizadas después por todos los escritores que se han ocupado en ese periodo. En el ensayo sobre Patiño, su raza recibe más énfasis para mostrar la viveza de los indios y lo razonable de la polftica española al animarlos a entrar en la sociedad criolla; si bien la experiencia de Patiño al tratar de hacerse académico reveló el prejuicio criollo contra su raza. El mayor elogio de Revilla se dirige hacia los maestros extranjeros que fueron traídos a México para enseñar el arte en la reorganizada Academia de San Carlos: Clavé, Vilar, Cavallari, y Landesio. Revilla revela su propia habilidad al hacer agudos juicios sobre la historia de arte; relaciona el estilo de Landesio con la larga tradición italiana de paisaje clásico, que extiende atrás hacia Poussin, aunque Landesio era "más apegado al natural... y buscaba la verdad en consorcio con la grandiosidad y la elegancia". No se puede hallar una descripción más elocuente del estilo de Landesio. Como académico, Revilla creía en la eficacia de los métodos rigurosos de enseñanza usados por Landesio, aunque consideraba que éste sólo había logrado dos alumnos distinguidos: Luis Coto y José María Velasco. Las Obras no dicen más de Velasco, pero en el año de la muerte del artista, en 1912, le dedicó un ensayo especial. En él elogia su comprensión poderosa del espacio mexicano, aunque aparentemente lamenta su desviación de las tonalidades ricas y armonizadas y el claroscuro dramático de Landesio. Revilla trataba de dar crédito a los artistas mexicanos cuando lo mereciesen, sin embargo siempre creía que las buenas cualidades del arte mexicano se debían a los maestros extranjeros. Su poca estimación de Cordero vis-a-vis de Clavé ejemplifica su prejuicio en favar de todo 
lo europeo tan típico del porfiriato. Aunque en sus escritos incluia el arte y la historia, los dos nunca se juntaban verdaderamente. Su historia apoyaba la teoría de los "grandes hombres", un rasgo corriente de su época (por ejemplo W. S. Robertson, The Rise of the Spanish-American Republics as Seen in the Lives of Their Liberators, 1918). En su discusión del arte da bastante menos espacio a las biografías mismas, pues trata a los artistas como crítico contemporáneo, no como historiador de arte, ya que no admite un cambio en el gusto a causa del desarrollo histórico.

Del choque al antiguo régimen dado por la Revolución de 1910 resultó que muchos académicos rogaban por la continuación del pasado, mejor que por la ruptura violenta ya empezada por los sucesos radicales. El director de la Academia, don Jesús Galindo y Villa, en su discurso de jubileo de 19I3, esperaba que "el periodo de desórdenes" ya se terminase y que la Academia pudiese regresar a sus antiguos métodos, los cuales ni juzgaba ni criticaba. De mayor significación es el intento de Manuel Álvarez, un arquitecto académico, de parar la venta de las obras académicas, por debajo de su valor mercantil europeo. Hace una defensa vigorosa de la calidad de la pintura mexicana del siglo xIx, diciendo: "los cuadros de la escuela de Clavé y de Pina son de todo mérito", y comenta que la apreciación de ellos había decaido, aún en la administración académica. Su rechazo, demasiado enfático, del talento indio (ignora a Patiño) suena como el grito de una causa perdida. Después de la caída del general Huerta en 1914, la Academia, desacreditada, fue olvidada por espacio de unos veinte años.

Aún entre los escritores conservadores la Revolución comunicaba un nuevo sentido del valor de la contribución mexicana a su propia historia del arte. Don Francisco Pérez Salazar, cuyos origenes aristocráticos y buen gusto de conocedor recuerdan al académico anterior a la Revolución, escribió una historia de miras limitadas sobre el arte de Puebla, sin mencionar influencias ni extranjeras ni capitalinas. Por el contrario, sus esbozos biográficos de artistas poblanos hacen pensar que la evolución del estilo regional fuese resultado solamente de la influencia de los precursores poblanos. El pintor neoclásico Julián Ordónez, fun. dador de la Academia Poblana, cuyos orígenes y preparación no menciona, recibe el crédito de pintar con "mucho sabor regional". Pérez Salazar no se explica por qué Agustín Arrieta, quien había sido discípulo de Ordóñez, rechazó "los trazos marcados por la costumbre", y no "se encerró en el círculo estrecho de las obras místicas". Sólo opina que éste 
sinceramente trataba de expresar el espíritu de su época, y dice: "ha contribuido con su esfuerzo a formar patria". Pérez Salazar parece estar influido por el nacionalismo posrevolucionario en su escrito de 1926, reeditado en 1963, la Historia de la pintura en Puebla, aunque no lo menciona la excelente y larga introducción por Elisa Vargas Lugo.

Pérez Salazar continuaba el método de Revilla, de biografías detalladas y crítica artística breve, en sus estudios cuidadosos de la historia de arte de una región que incorporaban artistas no académicos. Tal interés dio una nueva dirección al estudio de arte mexicano, que culminarla en 1942 en las exposiciones de artistas regionales populares del siglo XIX. Directamente derivado de los escritos de Pérez Salazar es el libro Pinturas poblanas (siglos xvir-xviII), publicado en 1943 por José Luis Bello y Gustavo Ariza. Además de ilustrar una gran cantidad de cuadros (muchos de ellos de la Colección Bello), el libro no hace sino repetir, en el texto sobre los artistas, los datos ya conocidos por las investigaciones de Pérez Salazar.

Dando énfasis como Pérez Salazar a la independencia y la originalidad de los artistas mexicanos, el estudio sobre Velasco, pintor cristiano, de 1932, por Luis Islas Garcia, sigue esa corriente de opinión. Atribuye là calidad artística de Velasco a su rigor moral y a su creencia católica, que llenaban sus lienzos con una serenidad que reflejaba la gloria de la creación de Dios. Distingue entre "los extraños teñidos rosados" empleados por Landesio en sus paisajes mexicanos y la verdadera observación "honrada" que se ve en la obra de Velasco. Sin afirmar más que Velasco "era independiente", Islas García rechaza enfáticamente la idea de que pintaba "en una manera realista" porque implicaria que Velasco seguia una escuela europeizante. Por eso piensa que Velasco nada debia ni a su maestro académico romántico, ni a los realistas contemporáneos franceses. Según Islas García, tan sólo el apego al paisaje mexicano y la inspiración divina pueden explicar la grandeza de los lienzos de Velasco.

Mucho más sintomático de los años veintes posrevolucionarios era un puñado de escritores que odiaban la experiencia académica del siglo xIx. El libro más importante de ese grupo, publicado en 1927, fue la Historia del arte en México, por José Juan Tablada, un "periodista" (asf lo llamó Islas García), poeta y crítico de arte, cuya mayor preocupación era interpretar la cultura mexicana. Esa primera historia continua del arte mexicano acentuó los tres grandes periodos: el precortesiano, el colonial y el actual, y se limitó a considerar en once páginas la producción académica del siglo xix. Agresivamente nacionalista, Tablada rehuiso 
discutir a los artistas extranjeros, aún a los maestros famosos que guiaban el desarrollo de la pintura mexicana durante la segunda mitad del siglo xIx. Tablada regañó a los alumnos mexicanos de Clavé por no mostrar la vida verdadera, o sea los temas mexicanos. Consideraba que ese siglo produjo no más que cuatro maestros: Santiago Regull, José Salomé Pina, Félix Parra ("el rebelde del grupo académico", por su romanticismo y por su retrato indigenista de Las Casas) y José María Velasco. Todos los otros pintores, incluyendo a Juan Cordero, eran "menos que maestros", según Tablada, aunque aprueba a los académicos que trataban temas mexicanos, sobre todo indigenistas. Honra a Velasco con los títulos de "paisajista y mexicano... probo y honrado", pero está descontento con la interpretación insignificante que hizo Velasco del panorama mexicano, que "podía haber sido... pródigo, pintoresco y variado"; fue sólo "accidentalmente artista" por superar "el convencionalismo y el formalismo académico", que odia Tablada. Gracias a la influencia de un libro por "a young critic" (Justino Fernández), Tablada después revisó su opinión sobre Velasco, dando énfasis a "the cosmic significance" del esfuerzo del pintor para captar la esencia de la luz, "the same problem attacked by Einstein in terms of science".

Los artistas que participaban en el renacimiento artístico mexicano de los veintes cambiaron el enfoque de los estudios sobre el arte del siglo xix de los académicos al interés por los artistas populares. Empezó tal corriente en 1921 con el estudio del doctor Atl sobre lo que llamaríamos artesanfas modernas, como la alfarería, el tejido, juguetes, etcétera. Lo único de su contenido que considerariamos como buen arte es la obra de los grabadores como José Guadalupe Posada. Un poco más tarde, en 1925, Posada recibió la atención de un primer artículo por Jean Charlot, artista francés que se unió a los muralistas mexicanos al principio del movimiento. Posada le pareció "un precursor del movimiento de arte mexicano", a causa de su fuerte "expresión directa", evitando lo pintoresco y la virtuosidad, y su "dynamic symmetry", tan lejos de las posturas de la Academia. En el año siguiente Charlot llamó la atención sobre los grabados de Manuel Manilla, el precursor y maestro de Posada en la Editorial Vanegas Arroyo, que "fusiona armoniosamente ingenuidad voluntaria y sabiduría humilde" para crear "efectos dinámicos" de concepción "monumental". Fil entusiasmo de Charlot al analizar los grabados de Manilla no convence al lector de su grandeza, sino de la persuasiva retórica de Charlot.

El caso de Posada se renovó en 1928 gracias a la norteamericana 
Frances Toor en la revista que editaba, Mexican Folkways, en donde publicó varios "corridos" tal como habían aparecido, sobre papel de color, con grabados, bordes recortados y textos. Su mayor esfuerzo en relación con Posada fue la publicación, en 1930, de la gran monografía que incluyó todos los grabados entonces conocidos, pero faltaban los bordes, textos, y colores. En la introducción bilingüe Diego Rivera condena enfáticamente la tendencia "negativa" en el arte mexicano de imitar patrones extranjeros para agradar a la burguesía (un ataque frontal a la Academia) pero alaba la tendencia "positiva" encontrada en el arte popular que concordaba con las masas productivas. Según su juicio, Posada fue el más grande artista de este grupo, puesto que su arte, "libre hasta de la sombra de una imitación, tiene un acento mexicano puro". Con su combinación de movimiento y de equilibrio, es como "el arte clásico mexicano, es decir, el precortesiano", en su "amor al carácter y el empleo, a la vez terrible y drolático, de la muerte, convertida en elemento plástico".

Roberto Montenegro, otro artista revolucionario, abrió una nueva dirección al apreciar el arte no académico del siglo xix en su monografia de 1933, engañosamente intitulada Pintura mexicana (1800-1860). En esencia es un libro fotográfico, ilustrado con pinturas anónimas, con excepción de las obras del tapatío José María Estrada; según el autor, su empeño fue, sencillamente, presentar estos cuadros, para darlos a conocer. Sin embargo, el breve texto afirma que esos lienzos lograron un carácter verdaderamente mexicano, antes de que éste fuese destruido, después de 1860, por la influencia extranjera en la Academia. Su representación intensiva de la realidad, eliminando el fondo irrelevante, recuerda a Montenegro la obra de Henri Rousseau, el primitivo francés tan estimado por la Escuela de París. Aunque la semilla que sembró Montenegro no maduró en una estimación extendida de los artistas populares sino hasta una década más, todos los escritores posteriores reconocen en Montenegro la fuente de inspiración.

A mediados de los años treintas, estudiosos del arte mexicano, asI como algunos artistas, empezaron a considerar seriamente el grabado mexicano del siglo xrx. En 1933, Enrique Fernández Ledesma, bibliófilo y director de la Biblioteca Nacional, esbozó el papel importante en el desarrollo del grabado que había jugado don Ignacio Cumplido, un editor importante, como después lo fue en otra dirección Vanegas Arroyo. Un año más tarde, Fernández Ledesma hizo un estudio crítico de la tipografía del siglo xix en la capital. El fundador de la historia de 
arte en México, don Manuel Toussaint, antes preocupado con lo colonial o lo contemporáneo, publicó en 1934 su investigación única sobre el siglo xix, sobre el tema del desarrollo de la litografía en la República. Con razón identificó a Claudio Linati como introductor de ese proceso en México, y reunió datos de los editoriales y periódicos mexicanos que usaban el método. En 1938 Francisco Díaz de León resumió estas investigaciones en un estudio de la tradición litográfica del país. Salvador Toscano, un especialista en arte precolombino, en 1937 mencionó brevemente el romanticismo y su expresión en la tipografía y la litografía. En una nota López Malo elogió la pintura popular por su expresión de romanticismo y negó el valioso papel de la Academia en aquél. Antes de 1938 no habia una investigación inteligente sobre el grabado académico, pero la vino a hacer Justino Fernández. Mientras que prefiere decididamente los finos grabados hechos por Gil y sus alumnos durante el crepúsculo de la época colonial, incluye también muchos datos sobre la reorganizada enseñanza del grabado, dirigida al principio por el europeo Periam, mas pronto entregada a su hábil alumno Luis Campa. Fernández señala que la decadencia del grabado resultó de la creciente popularidad de la litografía, como el medio más fácil para dibujar, dejando a los grabadores académicos sin otro camino que copiar con cuidado otras obras de arte.

Durante el mismo periodo varios historiadores de arte, estudiosos serios, encabezados por Toussaint, crearon el Instituto de Investigaciones Estéticas, para fomentar en el futuro el estudio del arte mexicano. En 1937 apareció la primera edición de sus Anales, que aumentó el conocimiento de muchos aspectos del arte, por los artículos que presentan documentos, obras de arte, y novedades de investigación. Los Anales siguen siendo la fuente de mayor importancia para informes sobre arte mexicano.

El primer libro de importancia publicado por el Instituto incluyó al siglo XIX en la historia general del arte mexicano desde la fundación de la Academia (1781) hasta el año de la publicación (1937) del volumen por Justino Fernández. Resumiendo el asunto de las influencias extranjeras en la Academia, un tema evitado por Tablada, Fernández aprovechó las biografías de Revilla para los datos básicos. Antes de que apareciera este libro, Genaro Estrada en 1935 ya dio a conocer un grupo de documentos relacionados con la Academia en el siglo xvili. Arturo Arnáiz y Freg publicó en los Anales de 1938 un grupo de documentos que Fernández ya había incorporado a su estudio. Fernández ligó los 
documentos de Estrada y de Arnáiz y las biografías de Revilla en una historia continua, dividida en "pláticas" sobre periodos cronológicos.

No obstante el nivel razonable de la discusión, surgen muchos conceptos mexicanistas en la historia. En el caso de Patiño Ixtolinque, siempre un buen indice de indigenismo, declara Fernández que "merece un lugar especial" en la historia de arte a causa de su raza, pero añade el crítico correcto que Patiño nunca alcanzó el alto nivel de su maestro Tolsá, quizás porque escapó de las severidades del neoclasisismo. Además, Fernández dramatiza el conflicto entre los mexicanos como Cordero y Rebull y el maestro extranjero Clavé, que controlaba tanto a cada alumno que "no permitió que se desarrollara la personalidad". Pero todos los extranjeros no reciben mal tratamiento; Fernández afirma que después de la salida del arquitecto italiano Cavallari, en 1864, "Ia arquitectura decae notablemente y muy pocas obras de valor se realizan". Por lo general, su historia está construida alrededor de las vidas de unos artistas importantes, cuyos discípulos sólo se mencionan en lista. Las obras mismas de arte las discute rápidamente y en términos generales. Tan importante como es para la compilación y renovación de los datos acerca de la creación de arte moderno en México, el libro en realidad se preocupa más por la historia de la Academia que por el arte que ésta producía.

También muy preocupado con la Academia del siglo xix, Abelardo Carrillo y Gariel desde 1939 reunió datos sobre la historia de ésta. Su primera publicación se compone de las cartas y los Estatutos de la Academia desde su fundación hasta su papel bajo el Segundo Imperio. Carrillo y Gariel escribe sólo el mínimo de texto para ligar los documentos, los cuales se explican bien por sí mismos. Más tarde, en 1944 y 1950, publicó catálogos cronológicos de las colecciones de las galerías de arte en San Carlos. Aunque se pueden criticar estos textos por su ausencia de interpretación, tienen gran valor por sus datos básicos, que permiten una concepción más aguda de la naturaleza y la importancia de la Academia.

Los años que comprenden la Segunda Guerra Mundial produjeron la realización del pensamiento de los años anteriores sobre lo mexicano. Se descubrieron otra vez muchos artistas no académicos del siglo xIx, sobre todo los "populares", en el término mexicano, que equivale a "primitivos" en el extranjero. Ramón Gaya, un expatriado español. 
en 1940 comparó los pintores mexicanos populares con los primitivos mundiales y los juzgó de menor calidad. Dice que los mexicanos, como todos los primitivos, no creaban sino copiaban, representaban. El mejor de los mexicanos, Estrada, aspiraba a la "hermosura artística, unida a esa respetuosidad, a esa ceguera por la naturaleza que es la característica de todos ellos". Inspirados por el aislamiento bélico, aparecieron en el Palacio de Bellas Artes dos exposiciones de artes regionales, que atrajeron el interés de la nación. En 1942 se exhibieron pinturas jaliscienses del siglo xIx, el mismo tema que había popularizado Montenegro hacia una década. Dos historiadores mexicanos destacaron sus origenes académicos. Francisco de la Maza, un historiador del arte, escribió una nota corta, en 1944, sobre la obra de Estrada, el mejor y más conocido del grupo, señalando las limitaciones de éste y su instrucción bajo el director de la Academia Tapatía, Uriarte. La exposición en una galeria, de pintores veracruzanos también en 1942, se amplió en Bellas Artes en 1944. Al comentar sobre aquélla de 1942, Justino Fernández acentuó las relaciones académicas del grupo, cuyo pintor más importante, José Justo Montiel, fundó una academia en Orizaba durante los años cuarentas, de donde muchos de sus alumnos salieron posteriormente para entrar en San Carlos. En su crítica a Montiel, Fernández elogió los cuadros que más se parecian a la obra de maestros europeos como Ingres y Degas.

Dos historiadores extranjeros, en su entusiasmo por apoyar lo más típico del arte mexicano, escribieron sobre los mismos pintores populares, pero alabaron la desviación de ellos de los patrones europeos académicos. Apreciaban el aplanamiento naif de las formas tridimensionales y el abstracto juego resultante de las áreas de colores y de los contornos expresivos. Walter Pach, un historiador de arte y crítico norteamericano, publicó la primera presentación del pintor guanajuatense Hermenegildo Bustos, a quien considera una continuación del genio mexicano antiguo, pero con una nueva humildad, sinceridad, y sentido de la realidad. Aunque Pach señala unas de sus obras más realistas, que muestran una gran habilidad como dibujante y como delineador de carácter, francamente prefiere retratos y bodegones menos realistas los cuales tienen una intensidad que "evoca lo universal en contraste con lo particular".

Paul Westheim, un emigrado alemán historiador y crítico de arte, quien había escrito un libro importante en alemán sobre el grabado en madera del gótico tardío, más tarde traducido al castellano y ampliado para incluir a los mexicanos, se enamoró de los aspectos más primitivos del arte mexicano: el precortesiano y el popular. Observando la expo- 
sición de los pintores veracruzanos en 1944, se entusiasma con los contornos animados y con la manera de "colocar esta silueta sobre el fondo negro irreal", visto en rígidos grupos familiares. Rechaza a Montiel, el único identificado, puesto que, siendo un poco más tarde que los otros, "ya trataba de lograr efectos con las tonalidades, los "valores" ". Dice, sin embargo, que todos tienen una expresión lineal que les da una calidad sobrerreal, o un realismo mágico, como en las obras de Henri Rousseau. En un ensayo de 1948 que dedicó a Estrada y a Bustos, Westheim encuentra las mismas cualidades en estos artistas, resultado, él cree, de su situación "medieval" como "obreros" comisionados por la burguesía para hacer un recuerdo documental. La observación intensiva y fresca de aquellos pintores en los detalles crea la abstracción sobrerreal que admira tanto Westheim. Condena el eclecticismo "snob" de los pintores académicos que, al haber obscrvado tantos cuadros, ya no podian ver la realidad física de su tema.

Durante el mismo periodo de la Segunda Guerra, los grabados de Posada fueron objeto de una gran exposición en Bellas Artes, en 1943, que inspiró una serie de elogios provenientes de todas las Américas. Entre esos autores están el argentino Luis Seoane, el texano Loren Mozley, el español Ramón Gaya y los mexicanos Arsacio Vanegas Arroyo, Mada Ontañón y Justino Fernández. Probablemente el elogio más profundo lo escribió Fernando Gamboa para la exposición norteamericana de 1944. En el texto de este catálogo analítico, Gamboa trata de hallar las influencias decisivas sobre el estilo de Posada, eso es una preocupación mayor de la historia de arte, pero poco aplicada antes a estudios mexicanos. Su conclusión, todavia expresada en términos nacionalistas, concede que Posada, evidentemente, fue influido por sus primeros contactos con Trinidad Pedroza y Manuel Manilla, pero su obra muestra "no direct influences, although artistic traditions were not unknown to him. No shadow of European style is in his work, which is free from effects foreign to the national landscape". Gamboa con razón, critica la obra de Manilla como "rigid and hieratic", lo que atribuye a su descendencia india; y concluye así: "Manilla may not have known where he was going, but Posada showed conscious creation."

Francisco Díaz de León, un grabador distinguido, quien había escrito un artículo en 1938 sobre la litografía mexicana, aprovechó la exposición de Posada, en 1943, para comparar a éste con el grabador yucateco Gabriel Vicente Gahona, cuya obra habia descubierto. En un principio opinaba que Gahona sólo podía haber adquirido su excelente técnica ep 
Europa cuando era becario, pero empezó a dudarlo cuando descubrió que si bien el gobierno yucateco lo otorgó una beca en 1845, no habia fondos para cumplirla. Sin embargo, concluyó que la familia Gahona, estando en buena situación económica, probablemente lo envió a visitar Italia, donde adoptó el apodo de "Picheta". Díaz de León asegura que Gahona y Posada fueron los maestros más grandes del arte gráfico mexicano, tal vez porque ambos se comunicaban directamente con el pueblo por medio de sus obras de sátira social. Por fin, en 1947 Díaz de León publicó un artículo totalmente dedicado a Gahona, y al año siguiente Jaime Orosa Diaz lo siguió con una monografía sobre Picheta. En su mayor parte ésta trata de los hechos de la vida y la obra de Gahona y presta poca atención al arte, pero más a su técnica. Concluyendo esta serie, Leopoldo Peniche publicó Quince grabados de Picheta, en 1949.

Otras publicaciones sobre el grabado, editadas durante el periodo de la Segunda Guerra Mundial, incluyen Grabadores populares mexicanos, por José Rojas Garcidueñas, en 1943, y el artículo escrito en 1945 por Joaquín Fernández de Córdoba sobre la litografía del siglo xix en Morelia, que es el primer estudio del grabado regional. Lo siguió en 1948 la breve monografía por Víctor Ruiz Meza sobre la litografia en Toluca, que es un compendio de hechos no interpretados.

El libro más reciente sobre el arte gráfico regional es el publicado en 1960 por José Miguel Quintana, trata la litografía y la fotografía no como artes, sino como técnicas, entre otras que componían la industria de la imprenta en Puebla.

Volviendo una vez más a la introspección de los años después de 1941, podemos asegurar que la exposición de la obra de José María Velasco, 1942, en el Palacio de Bellas Artes, atrajo la atención del pás. Aunque el paisajista fue estudiante y maestro en la Academia, su obra tiene tal calidad e interés que el gusto antiacadémico posrevolucionario pudo aceptarla. Aunque aparecieron varios artículos sobre la exposición misma, no tenían gran interés para la historia del arte. El texto más importante relacionado con la exposición fue el de la monografia interpretativa de Velasco por el crítico español Juan de la Encina. En 1939, después de su llegada a México, contribuyó con un artículo para los Anales del Instituto de Investigaciones Estéticas, en el que señaló lo "goyesco" en el arte mexicano a causa de su búsqueda de la belleza en lo feo u horrible. En la monografía sobre Velasco, expone sus conocimientos de los movimientos artísticos europeos, para así poder interpretar las obras mexicanas, lo que equivale a un método poco usado por lat 
crítica mexicana. Hace una comparación interesante del punto de vista de Velasco con el paisaje de la Escuela de Barbizon, del realismo francés; pero ésta y otras comparaciones que hace son de carácter espiritual, no de relaciones propiamente históricas. Sin embargo, ese modo de ver el arte fue bueno en su momento, porque relacionó el arte mexicano con el mainstream del Mundo Occidental. No obstante, se podía esperar que De la Encina hubiera buscado la posibilidad de influencias de hecho, como recientemente se descubrió entre Seurat y Piero della Francesca, hacia tiempo reconocidos como almas afines. De la Encina se refiere a cuánto desdeñaba Velasco la pintura parisina, al verla durante su viaje en 1889, y así muestra su relación negativa con los impresionistas. Pero en esencia, De la Encina se queda en ensayista sobre el arte, no en historiador de éste, pues emplea la obra de Velasco como pretexto para largas desviaciones en las que filosofa sobre el arte en general. Su monografía, en todo caso, significó una actitud nueva, más internacional, más estética, hacia la historia del arte mexicano.

Otro estudio, durante la época de la Segunda Guerra, que también trató de los paisajistas, fue escrito en 1943 por don Manuel Romero de Terreros, un conocedor aristocrático y coleccionista de arte. Incluyó en su libro la producción académica de Landesio y de sus discípulos, como Velasco, cuyas obras eran bastante libres de fórmulas cuando trataba temas mexicanos. También introdujo la producción preacadémica de los viajeros europeos, quienes eran casi desconocidos por el mundo artístico mexicano. Estos comprenden a Charles Bowes, Edouard Pingret (costumbrista), Charles Byrne, y Pedro Gualdi (litógrafo de monumentos) . Aunque las obras de estos extranjeros le sirvieron esa vez como prólogo para el estudio mayor sobre Landesio y sus discípulos, Romero de Terreros más tarde amplió sus investigaciones para incluir a otros pintores. En 1949 publicó su estudio sobre la obra de Daniel Thomas Egerton, un artista inglés que pintó vistas de varias partes de la República entre 1834 y 1842. En 1953 publicó otro trabajo sobre los paisajes del segundo Barón Gros, pintados entre 1833-34.

Otros investigadores, entretanto, hablan descubierto a nuevos artistas extranjeros que pintaron "vistas" del México del siglo xix. En 1942 James Ford describió la obra de Conrad Wise Chapman; Federico Hernández Serrano escribió, en 1947, sobre Johann Moritz Rugendas; y en 1949 Justino Fernández dio noticia de una pintura del Zócalo por el Conde Octaviano d'Alvimar. En el artículo sobre Rugendas, el artista alemán que pintó muchos aspectos de Latinoamérica, Hernández Serrano 
sólo nos da datos de su vida, y clasifica su obra por temas. Las opiniones que incluye son de otros: lo dicho por Samiento, que "es historiador, más que pintor", pertenece al siglo anterior; solamente el comentario por Walter Pach, de una fuente no identificada, señala la importancia de la obra de Rugendas como afín a la de Delacroix. Con eso, Rugendas debe ser reconocido como el pintor más romántico que trabajaba en México.

Incorporando las investigaciones de otros y las suyas propias, Romero de Terreros hizo una síntesis, en 1959, que apareció a la vez en los Anales y en Artes de México. La mayor parte de su texto presenta los hechos básicos sobre la producción de arte, pero también hace comentarios críticos como, por ejemplo, que la luz de Landesio es falsa, demasiado dorada, y que la composición de Gros "está artísticamente ideada, y su ejecución nada deja que desear". Por lo general, estos juicios son iguales a los publicados en 1943.

Otros textos de Romero de Terreros, después de la Segunda Guerra Mundial, incluyen un articulo en los Anales del Instituto de Investigaciones Estéticas de 1946, de los bodegones y floreros pintados durante los siglos xvin y xıx, poniendo un énfasis en las obras de Arrieta. Dando el fondo histórico, Romero de Terreros traza la separación de los bodegones del siglo xvir como parte de escenas religiosas, hasta su existencia por sí. Ast, aplicar el buen principio histórico-artístico del Zeitgeist (el espíritu del tiempo), uno puede inferir la razón del cambio de Arrieta de los temas religiosos de su maestro académico, a los costumbristas. En 1956 publicó Antiguas haciendas de México, con los ejemplos ordenados de acuerdo con su función original. Este libro da solamente una historia del traslado de propiedades entre hacendados, sin sugerir, siquiera, cuando fueron construidos los edificios mismos; por lo demás, el libro incluye solamente descripciones. La misma información de Romero de Terreros es repetida por Garcia Lazo en Artes de México, en 1966, sin dar crédito a aquél. Así, la historia de arte en México todavía necesita un estudio de la arquitectura doméstica del siglo xix, que deberia proveer los datos básicos para una seriación estilística.

La publicación más reciente de Romero de Terreros es la de la colección de catálogos de las exposiciones académicas de San Carlos, en la segunda mitad del siglo $\mathrm{xIx}$, que eran semejantes a los "salones" franceses. Desgraciadamente no incluye un texto para interpretar ese gran cuerpo de información. En fin, se puede considerar a Romero de Terreros como un conocedor y anticuario que trae a la atención actual varios 
hechos olvidados del patrimonio artístico, pero que pocas veces trata directamente con problemas histórico-artisticos para aclarar la evolución de los estilos.

La revaluación del arte del siglo xix por fin se extendió al estilo académico cuando se exhibieron las obras de Juan Cordero en el Palacio de Bellas Artes en 1945. A pesar de su evidente dependencia de la técnica académica y de los temas tradicionales, la mayoría de los escritores sobre Cordero decidían olvidarlo; por el contrario, dieron énfasis a su independencia formal de la Academia bajo Clavé. La rivalidad entre Corderó y Clavé fue dramatizada; Cordero era un mexicano luchando para el dominio sobre el arte de su patria contra la intervención extranjera. Se señalaron las grandes pinturas murales de Cordero como precursoras del Renacimiento de la pintura mural del siglo xx.

Salvador Toscano, desviándose de sus estudios sobre el arte colonial y precortesiano, publicó un breve trabajo monográfico sobre Cordero en 1946. Después de leer su elogio de Cordero, se puede ver que Toscano no conocía bastante del arte del siglo xix, pues dice que Cordero era, "si no el pintor más inspirado de su época, sí, indudablemente, el más plástico", y que posefa "el más brillante colorido de nuestro siglo xix". También afirma Toscano que Cordero estaba excepcionalmente dotado antes de ir a Roma, pero que allí se le enseñó "un lenguaje fríamente neoclásico", que le dio "su estatismo, su inmutabilidad". Si Toscano no critica las limitaciones de Cordero, Xavier Villaurrutia aún menos, en su catálogo para la exposición de 1945 y en su artículo del mismo año. Toma sus datos biográficos directamente de Revilla. Los retratos que según Villaurrutia son sus mejores obras, le recuerdan los lienzos de Ingres, a causa de sus líneas melódicas y proporciones armónicas y la poca importancia del color. Sólo critica las composiciones ambiciosas y obras ostentosas, porque tienen menos valor que los retratos.

El tratamiento más importante que se dio a Cordero provino de Jean Charlot en un largo artículo en inglés; desgraciadamente fue reducido en extremo en su versión castellana. En contraste a sus reseñas de los años veintes sobre grabadores, ese estudio ya tiene una buena comprensión de las teorías histórico-artísticas. De los tres escritores a que nos hemos referido, solamente Charlot reconoce que "both Cordero and Clavé are now bedfellows, berthed within the style of a given period" y eran ambos "partisans of peinture d'histoire who told their noble stories through the same dignified puppets". Este artículo enfoca sobre la pintura mural de Cordero, en la que Charlot señala una evolución, desde 
la amplificación de la pintura de caballete, en la iglesia de Jesús María, llevada a su cumbre en la audaz concepción y técnica muralística de la iglesia de Santa Teresa, hasta el debilitamiento en su expresión en el suave romanticismo de la iglesia de San Fernando. Charlot da prueba a la idea corriente de que Cordero fue precursor de los muralistas actuales, puesto que en Santa Teresa sus formas eran audazmente simplificadas y los colores brillantes y puesto que usaba pintura barata al temple. No obstante, Charlot todavía mantiene algunos prejuicios mexicanistas, como, por ejemplo, la condenación del extranjero Clavé: "a superb executive, a moral zealot, and a mediocre painter", o su afirmación de que el hecho de haber fallado Cordero de apoderarse de la Academia "delayed by decades the coming of the Mexican school of art into its own".

La exposición de la obra del dibujante Julio Ruelas en 1946 produjo comentarios criticos de los mismos dos mexicanos que habían escrito sobre Cordero. El catálogo para Bellas Artes incluyó un texto por Salvador Toscano en el que se preocupa más por la importancia literaria de Ruelas, como cofundador del Modernismo en México, que por sus capacidades artísticas. A la vez que admite que Ruelas es dibujante excelente, sobre todo en la nueva técnica de aguafuerte y en la expresión de caracteres; da énfasis a los aspectos negativos de Ruelas como pintor inhábil que usaba colores monótonos, creaba paisajes inanimados, se preocupaba por "el amor y la muerte", y se ocupaba en "súcubos, fantasmas y monstruos". Mucho más comprensivo de Ruelas es el texto del catálogo para la exposición en Zacatecas, por Xavier Villaurrutia, pues es un crítico más sensible; dice, por ejemplo, que "su dibujo es nervioso y justo a un solo tiempo, minucioso y atormentado a la vez". También indica la relación artística entre Ruelas y el pintor suizo-alemán Arnold Böcklin, a quien conoció en Karlsruhe y "que halló en la obra del pintor fantástico una correspondencia, una afinidad espiritual". Ambos estuvieron ligados al movimiento Art-Nouveau, "más a la manera alemana que, por ejemplo, al modo francés". Villaurrutia de cierto parece más conocedor de las influencias europeas evidentes en Ruelas, que Toscano, por su mexicanismo, no reconoce o no quiere reconocer. Un artículo sobre Ruelas publicado en 1960 por Jorge Juan Crespo de la Serna, está más cerca del estilo de Toscano, por su interés literario, pero no añade nada nuevo sobre la crítica de su arte. El futuro de la historia del arte en México evidentemente está del lado del estilo crítico de Villaurrutia, con tanta complacencia por condenar como por elogiar. 
Solamente en la segunda historia del arte mexicano desde la Independencia por Justino Fernández se encuentra una revisión adecuada del arte del siglo $\mathrm{xIx}$, puesto que incluye un juicio estético con más sentido crítico y una situación del arte mexicano dentro de la estructura de la historia del arte occidental. Después de haber trabajado casi dos décadas antes sobre el arte contemporáneo, Fernández trae en este libro de 1952 muchas más interpretaciones de los hechos de las que había incluido en su primer libro de 1937. No solamente escoge las cumbres estéticas de la obra de todos los periodos y las analiza intensivamente, ilustrándolas en las márgenes del texto, sino que también incorpora los nuevos descubrimientos de los últimos quince años. Artistas como Rugendas y Ruelas, no mencionados en 1937, aquí reciben muchas páginas de intensivo análisis estético. Fernández menciona las filiaciones estilísticas del arte mexicano con el europeo, pero no las compara cuidadosamente con las fuentes, $y$ así no muestra la precisa naturaleza y grado de dependencia de un arte con otro. En realidad, con la excepción de las páginas al principio del libro en que se habla de los precursores europeos e indígenas que influyeran en la trayectoria del arte nacional, el texto no ilustra ni discute profundamente las influencias extranjeras sobre los artistas mexicanos.

Afirma Fernández que quiere discutir solamente "lo que tenga un valor que enriquezca positivamente la historia del arte y de la cultura". Por eso le interesa concentrarse sobre las obras de los artistas destacados; por ejemplo dedica treinta páginas a Velasco, pero sólo un párrafo sobre los compañeros de éste, igualmente hábiles pero menos originales. En su extenso análisis de Velasco, Fernández propone cinco etapas de su desarrollo, siendo la última la más "impresionista". De la Encina había evitado destacar tal desarrollo por etapas y sólo trató los cuadros por sus temas. En la historia de la escultura, Fernández no sólo identifica la bien entendida escuela de Vilar, sino también añade una escuela de Noreña, el discípulo de Vilar, que fue el responsable de las obras monumentales del Porfiriato en sus primeros años. El papel de Patiño Ixtolinque aparece disminuido, junto con toda la producción de aquel periodo de decadencia inmediatamente después de la Independencia. Así, el indigenismo emocional que caracterizaba la critica posrevolucionaria por fin parece haberse calmádo, igual que México bajo Miguel Alemán después de la Segunda Guerra, abandonó su aislamiento y vino a tomar parte más y más en la escena internacional. La pérdida resultante del sentido de su singularidad se refleja en la historia del arte, pues ya existe más criterio 
sobre los artistas nacionales y se admite la importancia de movimientos extranjeros en México.

Quizás la parte más débil del libro es en lo que toca a la arquitectura del siglo XIX, pero sin duda es resultado de la ausencia de estudios serios sobre el tema. Para mediados del siglo xix, Fernández ilustra nada más la obra de Cavallari y De la Hidalga, los mismos cuyas biografías escribió Revilla, y aunque insinúa que no discute a otros a causa de su baja calidad, es evidente que no podría haberlos incluido porque se desconocen sus obras. Lo que es sorprendente es que haya incluido tanta información sobre pintura y escultura igualmente desconocidas. En todo caso esta obra de Justino Fernández es la primera visión histórica continua que incluye todo el arte del siglo xix. Es tan importante que exigía una nueva edición, que acaba de aparecer (1967) incluyendo sólo los capítulos sobre el siglo XIX, con las ilustraciones en una sección de láminas al final, en vez de al lado de cada página como en la edición anterior; también tiene el libro una serie de láminas a color entre las páginas del texto.

Unos años después, Fernández prosiguió sus investigaciones sobre la litografía mexicana del siglo xix y publicó dos estudios. En el primero, de 1955, estudió un grupo de textos recopilados por Edmundo O'Gorman que trataban del establecimiento de la litografía en México por Claudio Linati y la inclusión de tal arte entre las materias de la Escuela de Bellas Artes. El texto se interesa más en lo literario e histórico que en lo artístico, como es inevitable para una lección de documentos. En el segundo estudio de 1956, se ocupa mucho más en lo estético, puesto que acompaña a una edición facsimilar del libro de los Trajes de 1828 por Claudio Linati. Aunque éste "constituye ese tipo de artista moderno, inaugurado por Goya, que expresa su mundo críticamente", Fernández ve que su estilo de dibujar es "clasicista". Funda este juicio en un análisis demasiado sencillo de cada litografia, señalando la composición, sea vertical o triangular, el color, y la expresión emotiva, no abstracta. Mucho más importante son sus investigaciones originales sobre la preparación europea de Linati. De sumo interés es el descubrimiento de la temporada en el taller de Jacques-Louis David, cuyos ideales y formas neoclásicos, absorbidos por Linati, impedían que captase el verdadero espiritu de México; así, interpretó los tipos del país con patrón clásico. El resto del texto trata de las opiniones de Linati sobre la situación política y social de su época. Fernández relaciona a Linati con las ideas revolucionarias francesas, tanto filosóficas como artísticas, y las utiliza para explicar los prejuicios en su interpretación de México. 
Ester Ciancas, una alumna (pero no la discípula) del Dr. Fernández, escribió una tesis de maestria en 1959 titulada: La pintura mexicana del siglo XIX. La mayoria de la tesis compone una recopilación de datos ya publicados en el libro de 1952 por Fernández. De vez en cuando la señorita Ciancas, una emigrada española, introduce algunas opiniones propias que reflejan su origen extranjero y un espíritu menos nacionalista que el del maestro. Incluye una evaluación moderada y bien juzgada de los académicos, aún Clavé: "no era mal pintor ... ni menos un mal maestro"; "los alumnos de Clavé lograron algunas buenas obras, aunque no sean muy del agrado del gusto actual. Con ellas nuestro país levantó su nivel artístico y cultural". Esta breve introducción precede a un catálogo larguísimo, alfabetizado, de todos los artistas conocidos del siglo xux, con sus datos biográficos y artísticos, asf como un temario de sus cuadros y su localización, pero con escasa crítica.

En 1953 apareció el primer ejemplar de Artes de México, una revista hermosamente ilustrada, dedicada a la popularización de las obras artísticas más importantes de todas las épocas de la historia mexicana. El texto multilingüe con frecuencia está fundado en trabajos anteriormente publicados en monografías o en revistas especializadas, condensados y despojados de sus datos académicos. Se ilustra con fotografías de alta calidad y gran tamaño, muchas veces las primeras adecuadas que se han publicado. La siguiente lista recoge los artículos que se refieren al siglo xix y en ella se indica el valor de cada texto $y$, entre paréntesis, los estudios sobre los cuales están basados:

Número 1 (1953): "Sentido del arte en el siglo xix", por Vladimiro Rosado Ojeda.

Número 4 (1954): "Los muralistas del siglo xix", por Raúl Flores Guerrero.

Numero 14 (1956): "The Mexican Lithograph in the 19th Century", por Fernando Leal. Una sintesis bastante creadora.

Número 21 (1958): "Vida y obra del grabador José Guadalupe Posada", con textos por Diego Rivera, Fernando Gamboa y Jean Charlot.

Número 28 (1959): "Los descubridores del paisaje mexicano", por Manuel Romero de Terreros.

Número 37 (1961): "Mercados y Mercaderes", incluyendo reproducciones de grabados por Casimiro Castro y J. Campillo.

Número 41 (1962): "Bodegones mexicanos del siglo xix", por Francisco Cabrera. Una obra creadora que incorpora estudios anteriores discutidos más adelante.

Número 47 (1963): "Viaje pintoresco y arqucológico sobre la parte más 
interesante de la República Mexicana en... 1829-1834", por Carlos Nebel. Buena reproducción de la edición de Sartorius.

Número 53/54 (1964): "La ciudad de México en el siglo xIx", con buenísimas reproducciones de litógrafos del siglo xix mostrando la arquitectura del periodo.

Número 61 (1965): "Pintura popular y costumbrista del siglo XIx", por Xavier Moyssén. Una excelente sintesis creadora de las investigaciones desde hace unas décadas, se la discute abajo.

Número 79/80 (1966): "Haciendas de México", por Joaquín Garcia Lazo. Derivado directamente de Romero de Terreros; discutido arriba.

Número 92/93 (1967): "Museo Nacional de Historia: Castillo de Chapultepec", con textos por Justino Fernández sobre pinturas murales y Xavier Moyssén sobre pintura del siglo XIX.

En 1956 la exposición, largamente atrasada, de los cuadros de Bustos inspiró dos monografías sobre su vida y obra, ambas publicadas en Guanajuato, estado natal de Bustos, e igualmente provincianas en calidad. El autor de una, Pascual Aceves Barajas, posee una colección particular de varias pinturas por Bustos. Este libro es biográfico, dando énfasis, en una prosa florida, a la humildad religiosa de Bustos $y$, al clasificar los temas de sus obras, a la identificación de las personas en los retratos, en vez de hacer crítica del arte. La otra biografía de Bustos, por Jesús Rodriguez Frausto, apareció en una serie consecutiva de cinco folletos, y mejora un poco la anterior. El autor intenta dividir la obra de Bustos en tres periodos, "Primitivo, Evolución y Plenitud", pero se le olvida definir la diferencia entre los últimos dos. Trata a Bustos no tanto como artista sino como fenómeno social, un "indio" cuyo arte integró todas las clases de la sociedad guanajuatense. Ambos escritores parecen haber desatendido el desarrollo de la historia de arte en la capital de los quince años anteriores.

Igualmente desatento a esos problemas histórico-artísticos ha sido José Guadalupe Zuno, en Guadalajara, quien muestra cierta falta de método. Su primer libro del siglo XIx, sobre Estrada, publicado en 1957, es a la vez su mejor obra, porque usa hechos bien organizados para soportar su teoría de que Estrada fuese un revolucionario que declarase la independencia de la pintura mexicana al mismo tiempo que el país ganó su independencia política de España. Más adelante aprovechó otros temas, sean de Posada o de los caricaturistas, no para proveer datos biográficos sino 
para escribir largas digresiones sobre lo que se le ocurre, en estilo "stream of consciousness".

Un antiguo artista de la Revolución Mexicana, Zuno, compone sus libros como lienzos expuestos más que como exposición lógica. Así, se encuentran impresiones generales, como en "la ironia plástica", sobre artistas, grabadores, caricaturistas, y a cualquiera que dibuje temas político-sociales. Al compararlo con otro ensayista como De la Encina, quien también aprovechó a un artista mexicano para elucidar sus ideas sobre temas generales, Zuno parece haber dado grandes pasos hacia lo irracional, tan bien expresado por su héroe Goya.

Como luz clara en la niebla de los años tardíos de 1950 aparece la obra de Francisco de la Maza, miembro importante del Instituto de Investi- . gaciones Estéticas, quien hasta 1957 se preocupaba por el arte colonial con la sola excepción de una nota breve sobre Estrada. Pero en los Anales de 1957 se trató el tema de la arquitectura porfiriana para identificar y definir edificios capitalinos del estilo Art-Nouveau. Introduce este estudio con una historia larga del estilo en Europa, dando énfasis a sus variedades regionales. Cuando afirma que la variedad francesa es la más semejante a la mexicana, hace precisamente el tipo de atribución necesaria para ligar fuertemente el arte mexicano con el del resto del mundo. Desgraciadamente, nunca prueba esta relación con Francia por comparaciones lado-al-lado de detalles arquitectónicos. Sin embargo, la significación de este artículo no puede ser exagerada, puesto que no solamehte relaciona el arte mexicano con el europeo considerándolos como iguales, sino que también trata la arquitectura mexicana del siglo xux, un tema evitado hasta entonces.

Prosiguiendo la elucidación de este último tema, Manuel González Galván en los Anales de 1960 identifica la obra de Carlos Z. Flores, un arquitecto-ingeniero local de San Cristóbal las Casas. Aunque sus edificios pertenecen probablemente al siglo $\mathrm{xx}$ (desgraciadamente no se fecha nada), González Galván señala, con razón, que fueron derivados de los cuadernos de Vignola, del siglo xvi. Prueba esta influencia al comparar los dibujos de Vignola con las fachadas de Flores, los cuales son de tamaño muy reducido. Es error, sin embargo, el que González Galván compare a Flores con los arquitectos neoclásicos, pues se relaciona "mucho más con los constructores del siglo xvin, como los del mundo británico, que basaron todas sus obras sobre libros que copiaron. Aunque Flores viajó solamente a Tabasco y Veracruz, ¿no podria haber influido en su gusto el blanco clasicismo imperial porfiriano? Entonces, quizás el arte 
de Vignola le dio los patrones más semejantes al estilo porfiriano. Si esto es razonable, entonces Flores no sería un anacronismo, y permitiria una generalización sobre el estado de la arquitectura provinciana durante aquel periodo.

En un artículo de los Anales de 1959, Francisco de la Maza extendió su interés a la escultura funeraria "Romántica" de mediados del siglo XIX, ejemplo de la cual descubrió en algunas iglesias yucatecas. Puesto que su nota breve no hace más que describir las piezas y rogar con pasión que se identifiquen y conserven y cosas semejantes, no intenta relacionarlas con estilos extranjeros. Que unas obras vinieran de Parls, habria merecido una investigación. El estilo neoático de todos los relieves (más neoclásico que romántico), como casi todos los estilos académicos de Europa y América, todavía espera una explicación artístico-histórica. Un artículo subsecuente en los Anales, por Eugenio Noriega Robles, evidentemente inspirado por el de De la Maza de cuatro años antes, contesta su ruego para la identificación y publicación de obras semejantes. En Tepic, Nayarit, encontró Noriega un relieve neoático importado de Italia que, por un estudio cuidadoso de los símbolos, se puede fechar en 1847 . Así, aunque ambos artículos presentan sólo datos, levantan la posibilidad de un estilo neoático panatlántico empleado exclusivamente para monumentos funerarios.

Xavier Moyssén hace una exposición de detalles desconocidos del siglo xux en un artículo de los Anales de 1961 sobre el pintor académico Isidro Martínez. Moyssén sí afirma que a la obra de Martínez le falta genio, siendo inspirada directamente por lienzos académicos. Como el caso del artículo sobre el arquitecto-ingeniero Flores, éste contribuye al entendimiento de artistas medianos mexicanos. Otro artículo por Moyssén, en los Anales de 1962, expone las teorlas estéticas de Landesio según sus propios escritos, pero no añade nada que no fuera ya publicado antes.

Mucho más valor tiene la discusión general hecha por Moyssén sobre la pintura popular y costumbrista del siglo xix publicada en Artes de México en 1965. Comparada con la edición más temprana de Francisco Cabrera, sobre los bodegones de Arrieta, la de Moyssén es un modelo de sensibilidad. Aunque Cabrera señala la preparación académica de Arrieta, muestra demasiado entusiasmo al calificarlo "pintor de raza" quien rompió el molde académico-religioso para retratar las calidades verdaderas de México. Al contrario, Moyssén desinfla la teoría de la generación anterior, continuada por Cabrera, a saber, que los artistas populares 
representan la esencia del pafs, no manchados por las tendencias europeizantes de la Academia. Moyssén enseña que todos los maestros populares recibieron instrucción de pintores establecidos, frecuentemente académicos de segundo rango. Pero también identifica el espíritu verdaderamente mexicano de los artistas populares, cuya obra "se muestra, en no pocas ocasiones, más rica e interesante, frente al arte formal de los artistas de la Academia" porque sus temas son más verdaderos en cuanto a la vida nacional y sus colores muestran una "energía vital" de "los más variados y violentos contrastes" que siempre podían controlar los artistas indigenas. Como es el primer estudio creador de Moyssén, resume mucho en su juicio de las investigaciones anteriores.

Otras publicaciones de los primeros años posteriores a 1960 dieron a los investigadores un gran cuerpo de datos. El libro editado en 1963 por Manuel Romero de Terreros en el que incorporó los catálogos de exposiciones que tenían lugar en la Academia de San Carlos entre 1850 y 1898 es citado aquí por contener no más que hechos, sin interpretaciones. Mucho más importante por su combinación de hechos y análisis es la obra de Justino Fernández, quien desde 1940 ha mostrado un interés en la evolución de la crítica durante el siglo xix. Escribió artículos monográficos en los Anales sobre los críticos López López y José Martí. En El hombre, de 1962, los integra Fernández en un estudio panorámico de la crítica posindependiente que se compone de tres secciones: críticos que vivian en el siglo $x i x$ y criticaban el arte de su tiempo; críticos del siglo $x x$ que trataban el arte del siglo anterior; y críticos que escribieron en el siglo $\mathrm{xx}$ sobre el arte contemporáneo. Puesto que Fernández da largas referencias de los textos de los propios autores, permite que se justifiquen o se condenen, mientras él trata de limitarse en sus juicios personales. Está bien así porque su propia obra ha jugado un papel grande en tal historia; se refiere asimismo, sencillamente, como "el que escribe". La objetivación en sus escritos ha aumentado bastante desde las pláticas biográficas del libro de 1937, caracterizado por el uso frecuente del "yo".

Siguiendo el interés del director del Instituto de Investigaciones Estéticas, en 1964 se publicaron tres volúmenes de fuentes escritas durante el siglo xix criticando el arte moderno de aquel tiempo. El estudio preliminar, por Ida Rodríguez Prampolini, es dos veces el tamaño de la sección correspondiente en El hombre, de Fernández, y trata el tema en forma muy original.

El cincuentenario de la muerte de José Guadalupe Posada alentó la pu- 
blicación, en 1963, de muchas reproducciones de sus obras, acompañadas de textos sobre su vida y arte.

El rango de la calidad de estos textos nos da la oportunidad de ver la influencia del desarrollo anterior de la historia de arte sobre este tema, antiguamente tan nacionalista. En realidad esta influencia ha sido poca. Sólo la publicación del Fondo Editorial de la Plástica Mexicana es más completa que la monografía de 1930. Ilustra las obras de Posada con impresiones de alta calidad, frecuentemente en colores del original, y las organiza según sus temas. Pero el texto anónimo, biográfico en gran parte, trata muy poco del arte y más bien en términos de su contenido social o político. Aún es más nacionalista una publicación semioficial de José Antonio Murillo Reveles, quien revive el viejo elogio de Posada como precursor del arte mexicano y de la revolución política. Al dar tanto énfasis al papel político de Posada, no deja nada a lo estético. Reemplazando calidad por cantidad, Murillo da como largo apéndice treinta y dos referencias de otros autores que tampoco tratan del aspecto artístico. En la búsqueda de un entendimiento artístico de Posada es mejor Luis Cardoza y Aragón; parece estar, paradójicamente, contra la historia y la crítica de arte, puesto que dice "porque se ha escrito mucho sobre el, nos deja solos frente a su obra; nos pone a conjeturar qué es". A pesar de este punto de vista, más tarde cita el estudio de Charlot sobre la periodización según el medio favorable. Los métodos histórico-artísticos sólo aparecen en los ensayos que acompañan una carpeta de grabados publicados por el Instituto Nacional de Bellas Artes. La calidad de estos ensayos no sorprende porque fueron escritos por unos de los creadores de la disciplina de la historia del arte en México: Paul Westheim y Justino Fernández. Aunque Westheim destaca lo popular en el arte de Posada, señala su relación con Manilla, ya que los dos artistas trataron la vida popular con dignidad, y así evitaron la "nota pintoresca o folklórica" de los costumbristas románticos. Fernández logra relacionar a Posada con el ambiente artístico finisecular que se empeñaba en abandonar el realismo para expresar la emoción; as empleó la calavera como símbolo del "mundo brujeril", y explica por qué rechazó Posada la técnica de la ilusión. Pero Posada se destacó de los otros artistas finiseculares por la fuerza de sus composiciones formales, hechas con estructuras y no con las líneas ondulantes del Art-Nouveau, ni con el estático academismo. Es una pena ver que, de estas cuatro publicaciones, sólo la última muestra una evolución fuera del nacionalismo biográfico que hemos encontrado en los primeros es- 
critos posrevolucionarios sobre Posada. Los primeros años después de 1960, han producido además una síntesis importante de la historia del arte. Jean Charlot regresó en 1962 al tema de la Academia con un estudio de su desarrollo de 1785 hasta 1915. A los datos documentales bien conocidos añade nuevos materiales visuales que encontró en la Academia, sobre todo los dibujos estudiantiles ejecutados por los que fueron posteriormente maestros, como Patiño y Pina. En su discusión de Patiño, ha mantenido Charlot su antiguo entusiasmo indigenista, ya disciplinado para crear una excelente biografía critica, Repasa los documentos dudosos que se refieren a la afirmación de que Patiño fuese indio puro, luego dramatiza su progreso por una serie de dibujos ejecutados en varias etapas de su adiestramiento académico y por fin discute a Patiño como director de la Academia durante la temporada cuando a ésta le faltaba dinero. En esta temporada se concentra Charlot porque cree que entonces el arte mexicano se dirigía hacia una expresión de sí mismo. Más tarde piensa que aquel mexicanismo fue interrumpido por la reorganización de la Academia, que trajo maestros extranjeros para enseñar el estilo europeo. Aunque el leitmotiv del libro es la fluctuación de lo mexicano, lo maneja Charlot con un sensible equilibrio, evitando la agudeza de sus escritos anteriores en los que condenó a Clavé. Sin embargo, Charlot rechaza la consideración de que la pintura porfiriana de temas históricos e indígenas indicase un interés verdadero en lo mexicano.

Artista e historiador trilingüe Charlot escribe con tanta habilidad que, aun cuando presente cuentos familiares, les infunde nueva vitalidad por su interés humano en los individuos, su arte, y sus métodos para enseñarlo.

La síntesis más importante de la década actual, sin duda, es la revisión realizada por Raquel Tibol, en 1964, de todas las artes desde la Independencia. Como simpatiza con los muralistas radicales, trata el arte académico del siglo xix en modo muy cansado y desafinado, faltándole entusiasmo e interés. La monotonía del texto resulta de no distinguir a los artistas importantes y creadores de los muchos francamente medianos. Aunque evidentemente deriva muchos datos en su texto de la revisión de Fernández, le falta el sentido crítico de la calidad de las obras. En vez de seguir la periodización sugerida por Fernández para la obra de Velasco, regresa a una de fuente no identificada, proveniente de Diego Rivera, donde "señalaba con justicia tres periodos bastante definidos en el desarrollo ascensional de la personalidad de Velasco: el académico. europeizante, el impresionista, y el periodo en que su capacidad crea- 
dora sobrepasa cualquier influencia, logrando expresiones absolutamente originales". Aunque el periodo "impresionista" corresponda precisamente a la época de los impresionistas franceses, se debe estar de acuerdo con De la Encina sobre que Velasco no tiene nada en común con ellos, sino más bien tiene un esperitu semejante a los realistas. Si su pincelada se libera bastante para poder considerarse impresionista, esto sucede en su último periodo, como señaló Fernández. Por lo visto, Rivera quisiera probar que Velasco empezó ligado a antecedentes europeos, pero que por fin sacudió aquellos lazos coloniales. Quizás en los años 30 hacía buen patriotismo, pero ahora resulta mala historia del arte como debe saberlo Tibol.

Con excepción de las introducciones históricas a cada época del arte mexicano, Tibol no se mete en el nacionalismo de estilo antiguo. Sólo menciona los hechos, como por ejemplo, Patiño era indio e insurgente, pero no intenta aprovecharlo como ejemplo. Al contrario, al caracterizar su arte, dice que tiene "resonancias barrocas". Muestra Tibol un deseo demasiado ansioso de encajar cada movimiento y artista mexicano en términos derivados de la historia del arte europeo. Desgraciadamente, sólo nombra a los maestros extranjeros que influyeron en artistas mexicanos, y no intenta describir los rasgos estilisticos de aquéllos ni señalar la naturaleza y el grado de aquellas influencias extranjeras. De esta manera Tibol dio un paso atrás y llevó el estudio del arte del siglo xix a su etapa anterior, de biografia e historia sobre el arte. Solamente las ilustraciones, de alta calidad, son un paso adelante.

El modo más importante de tratar la historia del arte mexicano que ha aparecido durante esta década fue introducido en la monografia sobre el pintor Pelegrín Clavé por Salvador Moreno, un artista e investigador. El pudo preparar un catalogue raisonné de todas las obras conocidas de Clavé, gracias a su descubrimiento de documentos, dibujos y pinturas de éste en su ciudad natal, Barcelona. Las excelentes ilustraciones hacen difícil entender el desprecio anterior por la pintura de Clavé. Liberado Moreno de la ampulosidad de "nacional contra extranjero", los mexicanos actuales ya pueden ver por qué eran tan entusiastas Couto y sus compatriotas, de la obra del maestro catalán.

Lo único desafortunado es la ausencia de influencias documentadas sobre Clavé. Aunque Moreno cita los hechos de que Clavé estudió con Minardi en Roma, y allí admiraba el movimiento nazareno y el arte de su maestro Overbeck, no añade más que unos detalles verbales sobre la relación de Clavé con Minardi u Overbeck, sin ilustrar la obra de éstos. 
Repite la teoría de la influencia directa de Ingres sobre Clavé, antes propuesta por Fernández, sin apoyarlo por evidencia adicional. Quizás. sería demasiado pedir de Moreno, quien ha hecho una obra estupenda compilando los datos para este libro hermoso, que además intentara reconstruir el ambiente artístico romano en los años de 1830, una tarea jamás ensayada por historiadores europeos del arte, con la excepción de unas páginas por Pevsner. La historia del arte mexicano debe agradecer a Moreno haberla proveido de los primeros nuevos datos biográficos y artísticos sobre Clavé desde los de Revilla. Este reconocimiento quedará aumentado cuando aparezca la prometida monografía por Moreno sobre el amigo catalán y compañero académico de Clavé, el escultor Manuel Vilar.

De un suceso que ocurrió en la Universidad de Yale en 1966, podemos esperar que se dé una dirección nueva al estudio del arte mexicano. Fue una exposición del arte latinoamericano desde la Independencia, organizada por Stanton Catlin y Terence Grieder con intención de dar impetu a un punto de vista panamericano sobre el desarrollo artístico. Acompañando esa exposición tuvo lugar un simposio de las personas más importantes en el estudio del arte de cada país, con la esperanza de que el intercambio de hechos y opiniones clarificase los movimientos mayores. El libro esperado con los trabajos del simposio (todavía inédito) ya publicado tanto como el catálogo deberfan aumentar el impacto visual de la exposición que a principios de 1967 fue presentada en el Palacio de Bellas Artes, y dado el impacto de exposiciones anteriores en este lugar, se puede esperar un interés nuevo, ahora completamente ausente, en la relación de México con las repúblicas hermanas latinoamericanas en el campo de la historia del arte.

Es evidente que México ha hecho mucho durante las dos generaciones anteriores por entender su propia historia del arte, aunque todavfa falta bastante para integrar esta historia con la del mundo occidental. El modo biográfico de Revilla, fundado en hechos, ya está desplazado por la atención crítica dada al arte mismo, que a la vez se amplía con los hechos. La mayoria de los historiadores del arte mexicano han superado el nacionalismo extremoso que predicaba que mientras únicamente fuera mexicano el arte, tanto más alto sería su valor. Por eso elogiaban a los pintores populares y a los grabadores periodísticos al tiempo que regañaban a los maestros académicos europeizantes. Lentamente, con la apreciación de Velasco y Cordero, se admitió el arte académico del siglo xix, aunque todavia no se le admira suficientemente. Hoy día, mientras 
México se desarrolla más y más en la escena mundial, sus historiadores del arte empiezan a señalar las relaciones evidentes del arte mexicano del siglo XIX con los movimientos europeos, aunque están impedidos de hacerlo por falta de investigaciones sobre los movimientos académicos todavia impopulares en Italia, Alemania y España.

En fin, con el impetu dado en Norteamérica, con la exposición a que me referi más arriba, es de esperar que México y las otras repúblicas latinoamericanas empiecen a darse cuenta de las conecciones importantes entre si en cuanto a su historia común del arte durante el siglo xix y nuestro tiempo.

BibLiografia

A

Aceves Barajas, Pascual. Hermenegildo Bustos: Su vida y su obra. Guanajuato, Imprenta Universitaria, 1956.

Alvarez, Manuel Francisco. "Las pinturas de la Academia Nacional de Bellas Artes, su mérito artístico y su valor comercial." Memorias de la Asociación de Ingenieros y Arquitectos de México. México, 1914.

Angulo Iñiguez, Diego. La Academia de Bellas Artes de México y sus pinturas españolas. Sevilla, Universidad de Sevilla, 1935.

Antúnez, Francisco. Primicias litográficas del grabador José Guadalupe Posada. Aguascalientes, 1952.

Arnarz y Freg, Arturo. "Notas sobre la Academia de Bellas Artes de San Carlos." Anales del Instituto de Investigaciones Estéticas. México, UNAM, IIE, 1938, núm. 2.

ATL, doctor. Las artes populares en México. México, Libreria Cultura, 1921.

B

Bello, José Luis, Ariza, Gustavo. Pinturas poblanas. Siglos XVIII-XIX. México, Talleres Gráficos de la Nación, 1943.

C

Cabrera, Francisco. "Bodegones mexicanos del siglo XIX." Artes de México. México, 1962, núm. 41, año $x$.

Cardoza y Aragón, Luis. José Guadalupe Posada. México, UNAM, Dirección General de Publicaciones, 1963. Col. de Arte, núm. 15.

Carrillo y Garirl, Abelardo. Datos sobre la Academia de San Carlos de Nueva España. El Arte en México de 1781 a 1863. México, 1939.

- Las galerias de pintura de la Academia de San Carlos. México, UNAM, IIE, 1944.

-_. Las galerias de San Carlos. México, Ed. Mexicanas, 1950. Enciclopedia Mexicana de Arte, núm. 6. 
Catálogos de las Exposiciones de la Antigua Academia de San Carlos de México (1850-1898). Ed. Manuel Romero de Terreros. México, UNAM, IIE, 1963.

Gathin, Stanton L., Grieder, Terence. Art of Latin Ametica since Independence. New Haven, Yale University Press, 1966.

Ciancas, María Esther. La pintura mexicana del siglo XIX. México, 1959. Tesis para el grado de maestría de la Facultad de Filosofía y Letras de la UNAM (inédita).

Clıfrond, Henry. José Maria Velasco, 1840-1912. Philadelphia, Philadelphia Museum of Art, 1944.

Crespo de la Serna, Jorge Juan. "Julio Ruelas 1870-1907; perfil del hombre y su obra." Cuadernos Americanos. México, Ed. Cultura, 1960, núm. 5, año XIX.

Charlot, Jean. Cien grabados en madera por Posada. México, Ed. Vanegas Arroyo, 1947.

--.. "Juan Cordero, a nineteenth century mexican muralist." The Art Bulletin. Nueva York, The College Art association of America, 1946, vol. xxviII, núm. 4.

- "Juan Cordero, muralista mexicano." Hoy. México, 11 de agosto de 1945, núm. 442.

-... "Manuel Manilla, grabador mexicano." Forma. México, 1926, vol. 1, núm. 2.

- Mexican Art and the Academy of San Carlos, 1785-1915. Austin, University of Texas Press, 1962.

-2. "Un precursor del movimiento de arte mexicano: el grabador Posada." Revista de Revistas. México, 30 de agosto de 1925, núm. 25.

DENviR, Bernard. "Nineteenth-century mexican art." The Connoisseur. London, LGG Ramsey, may 1955.

Dfaz DE LEס́N, Francisco. "Gahona: un excelente grabador del siglo XIX." Revista de la Universidad Nacional Autónoma de México. México, UNAM, 1947, vol. I, núm. 4.

-.. "Gahona y Posada, intérpretes del pueblo.". Boletin del Seminario de Cultura Mexicana. México, 1943, vol. I, núm. 2.

- "Mexican litographic tradition." Mexican Art and Life. México, DAPP, Ed. Tablada, 1988, vol. III.

Documentos para la historia de la litografia en México. Recop. de Edmundo O'Gorman. Est. de Justino Fernández. México, UNAM, IIE, 1955.

"Documentos para la Historia de las Bellas Artes en México." Anales del Instituto de Investigaciones Estéticas. México, UNAM, IIE, 1937, vol. 1, nủm. 1.

$\mathbf{E}$

Encina, Juan de la. "De lo Goyesco en el Arte Mexicano." Anales del Instituto de Investigaciones Estéticas. México, UNAM, IIE, 1939, vol. I, núm. 4.

- El paisajista José Maria Velasco, 1840-1912. México, El Colegio de México, 1943. 
-_. "Velasco y el sentido del paisaje moderno." Letras de México. México, 1943, año vil, núm. 15.

Estrada, Genaro. Algunos papeles para la historia de las Bellas Artes en México. México, 1935.

Exposición en homenaje nacional a la memoria del genial grabador mexicano José Guadalupe Posada. México, SEP, 1943.

\section{$\mathbf{F}$}

FernANDez, Justino. El arte del siglo XIX en México. México, UNAM, IIE, 1967.

- El arte moderno en México. Breve historia. Siglos XIX y XX. México, Antigua Librería Robredo, José Porrúa e Hijos, 1937.

Fernández, Justino. Arte Moderno y Contemporáneo de México. México, UNAM, IIE, 1952.

-- . "La crítica de Felipe López López a las pinturas de la cúpula del templo de la Profesa." Anales del Instituto de Investigaciones Estéticas. México, UNAM, IIE, 1945, vol. Iv, núm. 13.

- - "De la critica del arte en México." Letras de México. México, 1940, vol. II, núm. 15.

---. "Descubrimiento de Posada." Excelsior. México, 4 de mayo de 1943.

- "El diario de Waldeck." Anales del Instituto de Investigaciones Estéticas. México, UNAM, IIE, 1954, vol. vi, núm. 22.

-- . "El grabado en lámina en la Academia de San Carlos de México durante el siglo XIX." Revista de la Universidad de La Habana. La Habana, Cuba, 1938, núm. 16.

- - El hombre. Estética del arte moderno y contemporáneo. México, UNAM, IIE, 1962.

--_. "José Justo Montiel: un pintor desconocido de mediados del siglo XIX." Anales del Instituto de Investigaciones Estéticas. México, UNAM, IIE, 1942, vol. II, núm. 8.

- - "José Martí como crítico de arte." Anales del Instituto de Investigaciones Estéticas. México, UNAM, IIE, 1951, vol. v, núm. 19.

--. "Una pintura desconocida de la plaza Mayor de México." Anales del Instituto de Investigaciones Estéticas. México, UNAM, IIE, 1949, vol. v, núm. 17.

FernAndez Ledesma, Enrique. "Don Ignacio Cumplido, apóstol de las artes gráficas." Viajes del Siglo XIX. México, 1933.

-.- Historia critica de la tipografía en la ciudad de México: Impresos del siglo XIX. México, SEP, INBA, 1934-1935.

FernÁndez de Córdoba, Joaquín. "La litografía moreliana del siglo XIX." El Hijo Pródigo. México, Ed. Letras de México, 1945, vol. x, núm. 32.

Flores Guerrero, Raúl. "Los muralistas del siglo XIX." Artes de México. México, 1954, núm. 4.

Ford, James. "Chapman." Gazette des Beaux Arts. Nueva York, 1942. 
G

Galindo y Villa, Jesús. "Nota informativa en el acto público de entregar la dirección de la Academia Nacional de Bellas Artes al sefior don Alfredo Ramos Martínez el día 15 de agosto de 1913." México, Tip. Mexicana, 1913.

San Carlos." Anales de la Academia Nacional de Bellas Artes de México. México, 1913, vol. I, núm. 9.

GamboA, Fernando. Exposición Hermenegildo Bustos, 1832-1907. México, SEP, INBA, 1952.

- Posada. Printmaker to the mexican people. Chicago, Art Institute, 1944.

Garcfa Lazo, Joaquín. "Las Haciendas Mexicanas." Artes de México. México, 1966, año XIII, núms. 79-80.

GAYA, Ramón. "Divulgaciones de un pintor: Introducción a la pintura mexicana." Romance. México, 19 de marzo de 1940 , año 1 , núm. 3.

- "El grabador Posada." El Hijo Pródigo. México, Letras de México, 1943, año I, núm. 1 .

Gonzhlez Galván, Manuel. "Vignola en San Cristóbal las Casas, Chiapas." Anales del Instituto de Investigaciones Estéticas. México, UNAM, IIE, 1960. vol. vinr, núm. 29.

GonzAlez Obregón, Luis. México viejo. Epoca colonial. México, Secretaria de Fomento, 1895. 29 ed., París, Vda. de C. Bouret, 1900.

Grabados populares mexicanos. Pról. de José Rojas Garcidueñas. México, UNAM, Imp. Universitaria, 1943 (impresión hecha por Carlos Alvarado Lang).

A guide to the art of Latin America. Robert C. Smith and Elizabeth Wilder. Washington, Library of Congress, 1948. (Hispanic Foundation, Latin American series, núm. 21.)

H

Hernandez Serrano, Federico. "Juan Moritz Rugendas y su colección de pinturas costumbristas." Anales del Instituto Nacional de Antropologia e Historia. México, SEP, INBA, 1947, nưm. 2.

Islas Garcfa, Luis. Velasco, pintor cristiano. México, Ed. Proa, 1932.

J

José Guadalupe Posada, ilustrador de la vida mexicana. México, Fondo Editorial de la Plástica Mexicana, 1963.

$\mathbf{L}$

LEAL, Fernando. "The mexican litograph in the nineteenth century." Artes de $M$ éxico. México, 1956, año Iv, núm. 14.

LrNat7, Claudio. Trajes civiles, militares y religiosos de México, 1828. Introd. 
Trad. y Est. de Justino Fernández. Pról. de Manuel Toussaint. México, UNAM, IIE, 1956.

López Malo, Rafael. "La pintura romántica del siglo XIX." Revisla de la Universidad Nacional Autónoma de México. México, UNAM, 1937, año III, núm. 12.

\section{$\mathbf{M}$}

Marfa y Campos, Armando de. "Orellana, Vargas Arroyo y Posada: creadores del mundo mexicano de los títeres." Romance. México, 1941, año II, núm. I.

Maza, Francisco de la. "Escultura Romántica." Anales del Instituto de Investigaciones Estéticas. México, UNAM, IIE, 1959, vol. vil, núm. 28.

-_- "José María Estrada." El Hijo Pródigo. México, Ed. Letras de México, 1944, vol. 17.

-_- "Sobre arquitectura Art Nouveau." Anales del Instituto de Investigaciones Estéticas. México, UNAM, IIE, 1957, vol. vir, núm. 26.

Montenecro, Roberto. Pintura Mexicana, 1800-1860. México, Secretaria de Relaciones Exteriores, 1933.

Moreno, Salvador. El pintor Pelegrin Clavé. México, UNAM, IIE, 1966.

Moyssên, Xavier. "Eugenio Landesio: Teórico y Crítico del Arte." Anales del Instituto de Investigaciones Estéticas. México, UNAM, IIE, 1963, vol. vII, núm. 32.

-_. "Isidro Martínez: Un pintor académico desconocido." Anales del Instituto de Investigaciones Estéticas. México, UNAM, IIE, 1961, vol. vir, núm. 30.

- "Pintura popular y costumbrista del siglo XIX." Artes de México. México, 1965, año xII, núm. 61 .

Mozhey, Loren. "A note on José Guadalupe Posada." The Library Chronicle. Austin, University of Texas, 1944, vol. I, núm. 2.

Murillo, Gerardo. (Véase Atl, Dr.)

Murn.lo Revekes, José A. José G, Posada. México, SEP, 1963.

$\mathbf{N}$

Norizca Robles, Eugenio. "Un sepulcro romántico en Tepic." Anales del Instituto de Investigaciones Estéticas. México, UNAM, IIE, 1963, vol. vili, núm. 32.

Núñez y Domínguez, José de J. “Un pintor alemán de cosas mexicanas. Rugendas." El Universal. México, 1927.

$\mathbf{O}$

Ontañón, Mada. "México en los grabados de Posada." Hoy. México, 24 de abril de 1943.

Orosa Dfaz, Jaime. Picheta. Mérida, Gobierno del Estado de Yucatán, 1948.

$\mathbf{p}$

Pach, Walter. "Descubrimiento de un pintor americano." Cuadernos Americanos. México, 1942, año 1, núm. 6. 
-. "Anewly found american painter: Hermenegildo Bustos." Art in America. 1943, vol. 31 .

Pacheco, Juan de M. Galerias de pintura de la Academia de San Carlos: indicador de cuadros. México, UNAM, 1932.

Pellicer, Carlos. "Los antecedentes." La pintura mural de la Revolución Mexicana, 1921-1960. México, Fondo Editorial de la Plástica Mexicana, 1960.

Peniche Vallado, Leopoldo. Quince grabados de Picheta. Mérida, Ed. Provincia, 1949.

Perez de Salazar, Francisco. Historia de la pintura en Puebla. Introd. Recop., y notas de Elisa Vargas Lugo. Revisión y notas de Carlos de Ovando. México, UNAM, IIE, 1963.

Pevsner, Nicolaus. Academies of Art; Past and Present. Cambridge, University Press, 1940.

$\mathbf{Q}$

Quintana, José Miguel. Las artes gráficas en Puebla. México, Antigua Libreria Robredo, 1960.

$\mathbf{R}$

Revilla, Manuel Gustavo. El arte en México. México, Secretaria de Fomento, 1893 (2a. ed., México, Ed. Porrúa, 1923.)

- Obras. Biografias (artistas). México, Ed. Agüeros, 1908 (Biblioteca de Autores Mexicanos, núm. 60.)

-_. El paisajista don José Maria Velasco. México, Escuela Tipográfica Salesiana, 1912.

[La] Revolución Mexicana vista por José G. Posada. México, Jaled Muyaes, Talleres Policromía, 1960.

Rivera, Diego. "José Guadalupe Posada." Revista de la Universidad Nacional Autónoma de México. México, UNAM, 1936, vol. Ir, núm. 11.

Rodríguez Frausto, Jesús. Hermenegildo Bustos. Guanajuato, Archivo Histórico, Universidad de Guanajuato, 1956 (biografías: 10-14).

Rodrf́guez Prampolini, Ida. La critica de arte en el siglo XIX. México, UNAM, IIE, 1964.

Romero De Terreros, Manuel. "Acuarelas mexicanas del siglo XIX." El Hijo Pródigo. México, Ed. Letras de México, 1944, vol. ni, núm. 10.

--. Antiguas haciendas de México. México, Ed. Patria, 1956.

-_. El Barón Gros y sus vistas de México. México, UNAM, Imp. Universitaria, 1953.

-_.. "Bodegones y Floreros en la pintura mexicana. Siglos XVIII-XIX." Anales del Instituto de Investigaciones Estéticas. México, UNAM, IIE, 1946, vol. IV, núm. 14.

-_. "Los descubridores del paisaje mexicano." Artes de México. México, 1959, año viI, núm. 28.

-_. "México visto por pintores extranjeros del siglo XIX." Anales deI Instituto de Investigaciones Estéticas. México, UNAM, IIE, 1959, vol. vir, núm. 28.

_... Paisajes mexicanos de un pintor inglés. México, Ed. Jus, 1949. 
Paisajistas mexicanos del siglo XIX. México, UNAM, IIE, 1943.

Rosano OJeda, Vladimiro. "Sentido del arte en el siglo XIX." Artes de México. México, 1953, año I, núm. 1.

Ruiz Meza, Víctor. Apuntes para la historia de la litografía en Toluca en el siglo XIX. México, Junta Mexicana de Investigaciones Históricas, 1948.

Salas Anzures, Miguel. "La ciudad de México, II: siglo XIX." Artes de México. México, 1964, año II, núm. 53/54.

Seoane, Luis. José Guadalupe Posada: Las calaveras y otros grabados. Buenos Aires, Ed. Nova, 1943.

Tablada, José Juan. Historia del arte en México. México. Ed. Águilas, 1927. núm. 3.

Tibol, Raquel. Historia general del arte mexicano. Epoca Moderna y Contempordnea. México, Ed. Hermes, 1964.

Toor, Frances. "Guadalupe Posada." Mexican Folkways. México, 1928, vol. Iv, núm. 3.

Toro, Alfonso. "Breves apuntes sobre iconografía de algunos héroes de la Independencia." Anales del Museo Nacional de Arqueologí, Historia y Etnografia. México, 1913, vol. 3.

Toscano, Salvador. Exposición Nacional Julio Ruelas (1870-1907). México, SEP, INBA, 1946.

- Juan Cordero y la pintura mexicana en el siglo XIX. Monterrey, Universidad de Nuevo León, 1946.

-... "El romanticismo en el grabado." Revista de la Universidad Nacional Autonoma de México. México, UNAM, 1937, vol. III, núm. 12.

Toussaint, Manuel. La litografia en México en el siglo XIX. México, Estudios Neolito, 1934.

Tovar y R., Enrique de. Juan Moritz Rugendas. Noticias sumarisimas acerca del famoso pintor viajero. Morelia, Universidad Michoacana, 1943.

Vanegas Arroyo, Arsacio. José Guadalupe Posada, 36 grabados. México, Ed. Vanegas Arroyo, 1943.

Villaurrutia, Xavier. "Juan Cordero." El Hijo Pródigo, México, Letras de México, 1945, vol. 1x, núm. 30.

- Juan Cordero, 1824-1884. México, SEP, 1945.

-2. "Julio Ruelas, dibujante y pintor." Julio Ruelas, 1870-1907. México, SEP, 1946.

W

Westheim, Paul. Das Holzschnittbuch. Postdam, 1921 (Ed. revisada, traducida y ampliada para incluir el movimiento mexicano). 
-_.. El grabado en madera. México, Fondo de Cultura Económica, 1954.

-_. "José María Estrada y sus contemporáneos." México en el Arte. México, 1948 , núm. 3.

- "Pintores veracruzanos." El Hijo Pródigo. México, Letras de México, 1944, vol. Iv, núm. 15.

-.. Ferndndez, Justino, Rodrícuez, José Julio. José Guadalupe Posada. 50 aniversario de su muerte. Pról. Horacio Flores Sánchez. México, INBA, Museo Nacional de Arte Moderno, 1963.

\section{Z}

Zuno, José Guadalupe. Las artes populares en Jalisco. Guadalajara, 1957.

- Don José Maria Estrada, padre de la Independencia en la pintura mexicana. Guadalajara, Instituto Tecnológico de la Universidad de Guadalajara, 1957.

- Historia de la caricatura en México. Guadalajara, Universidad de Guadalajara, 1961.

- Historia de las artes plásticas en Jalisco. Guadalajara, 1957.

—.. La ironia plástica en Jalisco. Guadalajara, 1958.

-_- Posada y la ironia plástica. Guadalajara, 1958. 